\title{
Plasma enhanced atomic layer deposition of gallium sulfide thin films
}

Jakob Kuhs, Zeger Hens, and Christophe Detavernier

Citation: Journal of Vacuum Science \& Technology A 37, 020915 (2019); doi: 10.1116/1.5079553

View online: https://doi.org/10.1116/1.5079553

View Table of Contents: https://avs.scitation.org/toc/jva/37/2

Published by the American Vacuum Society 


\title{
Plasma enhanced atomic layer deposition of gallium sulfide thin films
}

\author{
Jakob Kuhs, ${ }^{1}$ Zeger Hens, ${ }^{2}$ and Christophe Detavernier ${ }^{1, a)}$ \\ ${ }^{1}$ Department of Solid State Sciences, CoCooN, Ghent University, Krijgslaan 281/S1, 9000 Ghent, Belgium \\ ${ }^{2}$ Department of Inorganic and Physical Chemistry, PCN, Ghent University, Krijgslaan 281/S3, 9000 Ghent, \\ Belgium
}

(Received 31 October 2018; accepted 3 January 2019; published 31 January 2019)

\begin{abstract}
Gallium sulfide has a great potential for optoelectronic and energy storage applications. Since most of these applications require a high control over the layer thickness or a high conformality, atomic layer deposition is a promising deposition technique. In this work, the authors present a novel plasma enhanced atomic layer deposition process for gallium sulfide based on trimethylgallium and $\mathrm{H}_{2} \mathrm{~S} / \mathrm{Ar}$ plasma. The growth was characterized using in situ spectroscopic ellipsometry. It was found that the process grew linearly at a rate of $0.65 \AA$ \&cycle and was self-limited in the temperature range from 70 to $350{ }^{\circ} \mathrm{C}$. The process relied on a combustion reaction, which was shown by the presence of $\mathrm{CS}_{2}$ during in situ mass spectrometry measurements. Furthermore, the material properties were investigated by $\mathrm{x}$-ray photoelectron spectroscopy, $\mathrm{x}$-ray diffraction, and optical transmission measurements. The as-deposited films were amorphous and pinhole free. The $\mathrm{GaS}_{x}$ thin films had a transmittance of $>90 \%$ and a band gap of 3.1-3.3 eV. Published by the AVS.

https://doi.org/10.1116/1.5079553
\end{abstract}

\section{INTRODUCTION}

Gallium sulfide is a wide band gap semiconductor with two stable forms: $\mathrm{GaS}$ and $\mathrm{Ga}_{2} \mathrm{~S}_{3} \cdot{ }^{1,2}$ It has great potential for optoelectronic and photovoltaic applications. ${ }^{3,4} \mathrm{GaS}_{x}$ can also be used to passivate GaAs surfaces. ${ }^{5-9}$ Furthermore, alkaline earth thiogallates, such as cerium-doped $\mathrm{Sr}_{2} \mathrm{Ga}_{2} \mathrm{~S}_{5}$, could be used as phosphor thin films in electroluminescent displays. ${ }^{10,11}$ Finally, composites of $\mathrm{GaS}_{x}$ and carbon nanotubes can be used as anodes for lithium ion batteries. ${ }^{12}$ Until now, there are a lot of PVD (Refs. 5, 6, and 13) and CVD (Refs. 14-17) processes for $\mathrm{GaS}_{x}$. However, since most of the applications of $\mathrm{GaS}_{x}$ require either a high control over the layer thickness or a high conformality, atomic layer deposition (ALD) is a promising deposition technique. Especially for applications where a high control over the amount of $\mathrm{GaS}_{x}$ or the position of $\mathrm{GaS}_{x}$ in an electronic stack is required, ALD may play an important role.

ALD is a self-limited deposition method that is characterized by alternating exposure of the growing film to different chemical precursors and reactants, resulting in the sequential deposition of (sub)monolayers over the exposed sample surface. ${ }^{18-20}$ The self-limiting nature of the vapor-solid reactions ensures pinhole free inorganic coatings with a precise thickness controlled at the atomic scale and a superb conformality onto large scale substrates with complex topologies. To date, there are only few reports of ALD processes for $\mathrm{GaS}_{x}$. Recently, a promising $\mathrm{GaS}_{x}$ ALD process using hexakis(dimethylamido)digallium and $\mathrm{H}_{2} \mathrm{~S}$ was presented and applied as anodes for lithium ion batteries. ${ }^{21,12}$ This ALD process had a maximal growth per cycle (GPC) of $1 \AA$ /cycle at $125^{\circ} \mathrm{C}$ and an ALD window ranging from 125 to $225^{\circ} \mathrm{C}$. Recently, the same process was used in

Note: This paper is part of the 2019 special collection on Atomic Layer Deposition (ALD).

${ }^{a)}$ Electronic mail: christophe.detavernier@ugent.be combination with copper acetylacetonate to realize galliumcontaining sulfide ternary materials. ${ }^{22}$ Furthermore, an ALD process based on tris(dimethylamino)gallium and $\mathrm{H}_{2} \mathrm{~S}$ was predicted by investigating it theoretically with density functional theory calculations. ${ }^{23}$

Due to its high vapor pressure and high reactivity, trimethylgallium (TMG) should be a promising candidate for $\mathrm{GaS}_{x}$ ALD. However, even though thermodynamically favorable, no growth was observed using the thermal TMG $+\mathrm{H}_{2} \mathrm{~S}$ ALD process. ${ }^{21}$ Recently, the use of $\mathrm{H}_{2} \mathrm{~S}$ plasma instead of $\mathrm{H}_{2} \mathrm{~S}$ opened the possibility for new ALD processes. ${ }^{24-26}$ Especially, our previous results on plasma enhanced ALD (PE-ALD) of $\mathrm{Al}_{2} \mathrm{~S}_{3}$ are very promising for $\mathrm{GaS}_{x}$ ALD. ${ }^{26}$ The observation that thermal ALD of trimethylaluminum (TMA) $+\mathrm{H}_{2} \mathrm{~S}$ did not result in any growth while an ALD process could be established in combination with $\mathrm{H}_{2} \mathrm{~S}$ plasma motivated us to try a similar approach for $\mathrm{GaS}_{x}$ combining TMG with $\mathrm{H}_{2} \mathrm{~S}$ plasma.

In this work, we report on a PE-ALD process for $\mathrm{GaS}_{x}$ based on trimethylgallium in combination with argon diluted $\mathrm{H}_{2} \mathrm{~S}$ plasma as reactants. The plasma enhanced process showed linear and self-limited growth up to a temperature of $350{ }^{\circ} \mathrm{C}$, while the thermal process stopped growing after two ALD cycles. In comparison to the thermal processes based on hexakis(dimethylamido)digallium, this PE-ALD process offers a wider ALD window. Especially, the possibility to deposit $\mathrm{GaS}_{x}$ at a temperature as low as $70^{\circ} \mathrm{C}$ could be relevant for temperature sensitive applications. Based on an analyses of the reaction mechanism by mass spectrometry, it was found that a combustion reaction is taking place, producing $\mathrm{CS}_{2}$ as a reaction product. The structural and optical properties of $\mathrm{GaS}_{x}$ thin films deposited with PE-ALD were investigated. To the best of our knowledge, no PE-ALD processes for $\mathrm{GaS}_{x}$ were previously reported. Another advantage of this PE-ALD process is that it resulted in films with less impurities in comparison to the thermal processes based on hexakis(dimethylamido)digallium. 


\section{EXPERIMENTAL DETAILS}

$\mathrm{GaS}_{x}$ thin films were deposited in a home-built pump-type ALD reactor which was redesigned to be compatible with hydrogen sulfide following the suggestions described by Dasgupta et al. ${ }^{27} \mathrm{~A}$ detailed description of the used ALD system can be found in our previous work. ${ }^{25,26}$

$\mathrm{GaS}_{x}$ thin films were deposited by using TMG (>99\%, Strem) as precursor. As a reactant pure $\mathrm{H}_{2} \mathrm{~S}$ gas (for thermal ALD experiments) or $\mathrm{H}_{2} \mathrm{~S}$ plasma diluted by $\mathrm{Ar}$ (1:3) (for PE-ALD experiments) was used. The Ar dilution was used in order to minimize the exposure of the ALD reactor to the highly reactive sulfur radicals. The plasma was generated remotely from the substrate in a quartz tube surrounded by a copper coil using radio-frequency inductive coupling at $200 \mathrm{~W}$. The TMG precursor was stored in a not heated stainless steel bottle while the TMG line was heated to $40{ }^{\circ} \mathrm{C}$. Thin films were deposited on $\mathrm{Si}(100)$ wafers covered with native $\mathrm{SiO}_{2}$ or quartz glass. In order to estimate the conformality of the process, $\mathrm{GaS}_{x}$ thin films were also deposited on $\mathrm{Si}$ micropillars covered with $\mathrm{SiO}_{2}$. The maximal sample size of $3 \times 2 \mathrm{~cm}$ was determined by the size of the heater.

The substrate temperature was varied in the range of $70-350{ }^{\circ} \mathrm{C}$ using a proportional-integral-derivative controller. A standard ALD cycle consisted of $3 \mathrm{~s}$ precursor pulse followed by $25 \mathrm{~s}$ of pumping and $3 \mathrm{~s}$ of plasma pulse again followed by $25 \mathrm{~s}$ of pumping. The base pressure of the system was approximately $4 \cdot 10^{-6} \mathrm{mbar}$ while the process pressure of the TMG and $\mathrm{H}_{2} \mathrm{~S} / \mathrm{Ar}$ plasma pulses were $3 \cdot 10^{-3}$ and $1 \cdot 10^{-2} \mathrm{mbar}$, respectively. Since the pumping efficiency of TMG was very high and in order to increase the exposure of TMG, static TMG pulses were used for the conformality experiment on micropillars.

The optical properties of $\mathrm{GaS}_{x}$ and $\mathrm{ZnS}$ thin films were monitored in situ using spectroscopic ellipsometry (J. A. Woollam, M-2000). A Cauchy model was used in order to derive the $\mathrm{GaS}_{x}$ thin film growth rate from these optical properties. This model was verified by comparing the film thickness obtained from the spectroscopic ellipsometry measurements with the thickness obtained from ex situ x-ray reflectivity (XRR) measurements. Even during the first cycles of the film growth, good quality fits to the ellipsometric data were obtained.

Optical transmittance spectra of $\mathrm{GaS}_{x}$ deposited on quartz substrates were measured in the range of $200-800 \mathrm{~nm}$ with a Perkin-Elmer Lambda 950 spectrophotometer. The measured transmittance was corrected by the transmittance of the bare quartz substrate in order to obtain only the transmittance of the $\mathrm{GaS}_{x}$ thin film.

Furthermore, a mass spectrometer (HPR-30, Hiden) was used to analyze reaction products in situ during the ALD process. This mass spectrometer was connected to the chamber via a KF40 flange and a heated flexible tube.

The chemical composition of the deposited $\mathrm{GaS}_{x}$ films was determined by x-ray photoelectron spectroscopy (XPS). All measurements were performed in-house with a Theta Probe system from Thermo Scientific using $\mathrm{Al} \mathrm{K} \alpha$ x-rays generated at $15 \mathrm{kV}$ and focused to a spot size of $0.3 \mathrm{~mm}$ by an MXR1 monochromator gun. Argon etching was used in order to remove surface contamination and to investigate XPS depth profiles. This was done by using $\mathrm{Ar}^{+}$ions at an acceleration voltage of $3 \mathrm{keV}$ and a current of $2 \mu \mathrm{A}$. The obtained binding energies were calibrated using a binding energy of $284.6 \mathrm{eV}$ for the carbon peak. ${ }^{28}$

A Bruker D8 Discover using a $\mathrm{Cu} \mathrm{K} \alpha \mathrm{x}$-ray source and a linear detector was used to obtain $\mathrm{x}$-ray diffraction (XRD) and XRR patterns. Scanning electron microscopy (SEM) and energy-dispersive $\mathrm{x}$-ray spectroscopy (EDX) measurements were performed in an FEI SEM at an energy of $12 \mathrm{keV}$ using an energy dispersive $\mathrm{x}$-ray analysis silicon-drift detector from the company EDAX.

Atomic force microscopy (AFM) measurements were used to determine the surface morphology of the films. A Bruker Dimension Edge system operating in tapping mode in air was used. The root mean square (RMS) roughness was calculated from $2 \times 2 \mu \mathrm{m}$ scans.

\section{RESULTS AND DISCUSSION}

\section{A. ALD characterization}

The linearity of the plasma enhanced ALD process was investigated by depositing $\mathrm{GaS}_{x}$ thin films on a Si substrate covered with a native oxide. The film thickness was measured in situ during the ALD process using spectroscopic ellipsometry measurements. Figure 1 shows the estimated film thickness as a function of the ALD cycles for a thermal $\mathrm{TMG}+\mathrm{H}_{2} \mathrm{~S}$ ALD process and a TMG $+\mathrm{H}_{2} \mathrm{~S} / \mathrm{Ar}$ plasma PE-ALD process at a temperature of $100^{\circ} \mathrm{C}$. For the thermal ALD process, only a small increase of the layer thickness was observed during the first two ALD cycles. After that, no further growth was observed. This is consistent with results found by Meng et al., ${ }^{21}$ although thermodynamically a thermal TMG $+\mathrm{H}_{2} \mathrm{~S}$ ALD process should grow. Furthermore, it is in line with observations that a thermal TMG $+\mathrm{H}_{2} \mathrm{O}$ does

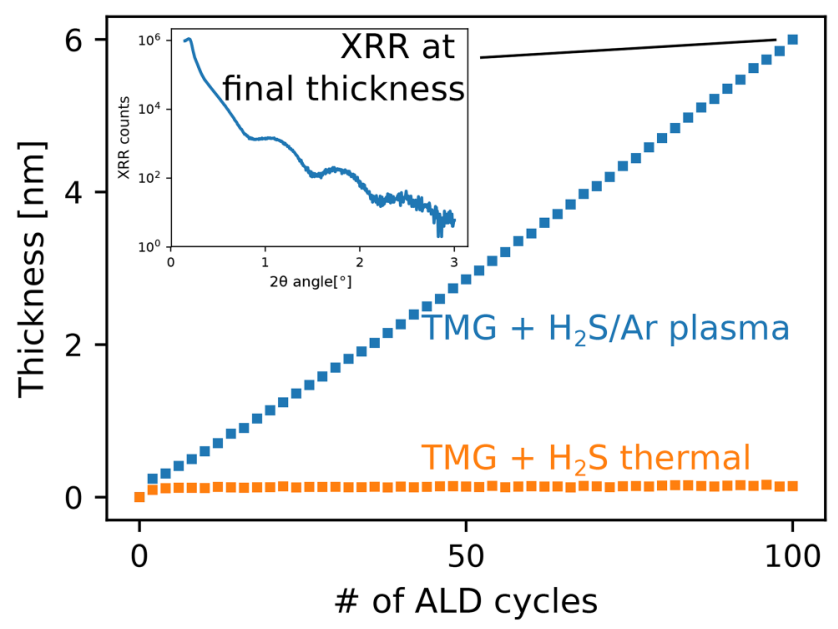

FIG. 1. Evolution of the film thickness vs the number of ALD cycles for the thermal $\mathrm{TMG}+\mathrm{H}_{2} \mathrm{~S}$ and the plasma enhanced $\mathrm{TMG}+\mathrm{H}_{2} \mathrm{~S} / \mathrm{Ar}$ plasma ALD process grown on $\mathrm{Si}$ covered with a native oxide at $100^{\circ} \mathrm{C}$. The growth of the thermal process stops after only two cycles while the plasma enhanced process continues growing linearly without any nucleation delay. The inset shows the XRR pattern at the final film thickness. 
not grow either. ${ }^{29}$ However, using a PE-ALD process where the $\mathrm{H}_{2} \mathrm{~S}$ pulse is substituted by a $\mathrm{H}_{2} \mathrm{~S} / \mathrm{Ar}$ plasma pulse resulted in a linear growth with no nucleation delay.

The TMG precursor was tested for thermal decomposition by just pulsing TMG at different substrate temperatures while measuring the increase in layer thickness with in situ spectroscopic ellipsometry. No growth due to thermal decomposition was found up to a temperature of $350{ }^{\circ} \mathrm{C}$. Figure 2 shows the ALD window of the TMG $+\mathrm{H}_{2} \mathrm{~S} / \mathrm{Ar}$ plasma PE-ALD process. In the range from 70 to $250^{\circ} \mathrm{C}$, the ALD window had a constant GPC of approximately $0.65 \AA /$ cycle. For temperature higher than $250^{\circ} \mathrm{C}$, the GPC started to drop and reached approximately $0.3 \AA$ /cycle at $350{ }^{\circ} \mathrm{C}$. Such a broad ALD window with a GPC which is constant over almost the entire ALD window has some advantages when different ALD windows have to be matched in order to realize ALD of ternary compounds. ${ }^{30,31}$

The self-limiting nature of the plasma enhanced ALD process was investigated by varying the pulse time of TMG and $\mathrm{H}_{2} \mathrm{~S} / \mathrm{Ar}$ plasma and measuring the growth rate in situ with spectroscopic ellipsometry. This was done at a low $\left(70^{\circ} \mathrm{C}\right)$ and a high $\left(350^{\circ} \mathrm{C}\right)$ temperature. Figure 3 shows the GPC as a function of the pulse time of TMG (circles) and $\mathrm{H}_{2} \mathrm{~S} / \mathrm{Ar}$ plasma (squares) for the PE-ALD process. At both temperatures, the maximum GPC was reached for TMG and $\mathrm{H}_{2} \mathrm{~S} / \mathrm{Ar}$ plasma pulse times of approximately $2 \mathrm{~s}$.

\section{B. Reaction mechanism}

The reaction mechanism was studied experimentally by investigating the reaction products of the thermal and PE-ALD $\mathrm{GaS}_{x}$ processes using in situ mass spectrometry. Figure 4(a) shows a schematic diagram of the sequence of the investigated gas pulses and ALD cycles. First three pulses of $\mathrm{H}_{2} \mathrm{~S}$ plasma, $\mathrm{H}_{2} \mathrm{~S}$, and TMG were investigated as a reference. Then, three cycles of the thermal TMG $+\mathrm{H}_{2} \mathrm{~S}$ process and three cycles of the plasma enhanced TMA $+\mathrm{H}_{2} \mathrm{~S} / \mathrm{Ar}$ plasma process were investigated. During these series, multiple ion detection mass

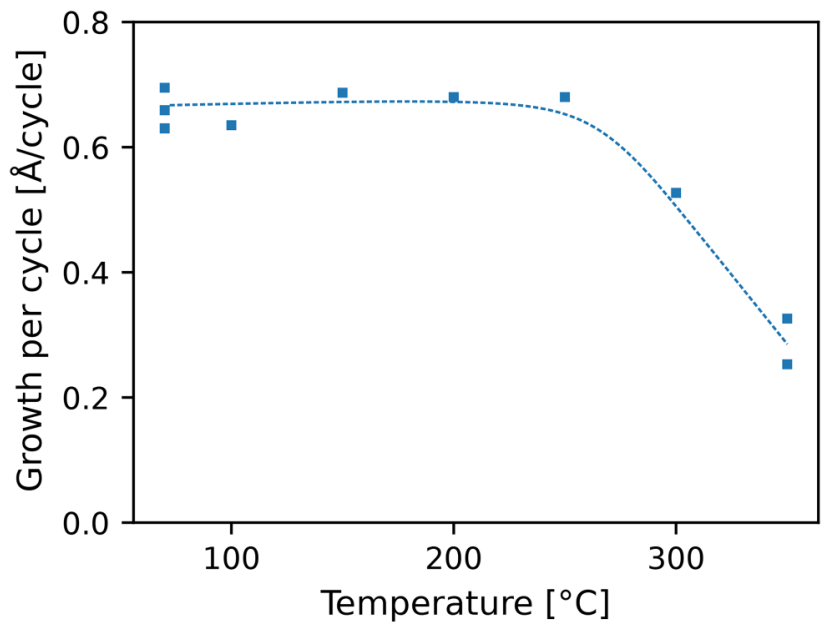

FIG. 2. Evolution of the growth per cycle as a function of the substrate temperature for the PE-ALD process of $\mathrm{GaS}_{x}$. The ALD window has a constant GPC of $0.65 \AA$ /cycle between 70 and $250^{\circ} \mathrm{C}$. For higher temperatures, the GPC drops down to $0.3 \AA$ /cycle at $350^{\circ} \mathrm{C}$. The dashed line is a guide to the eye.

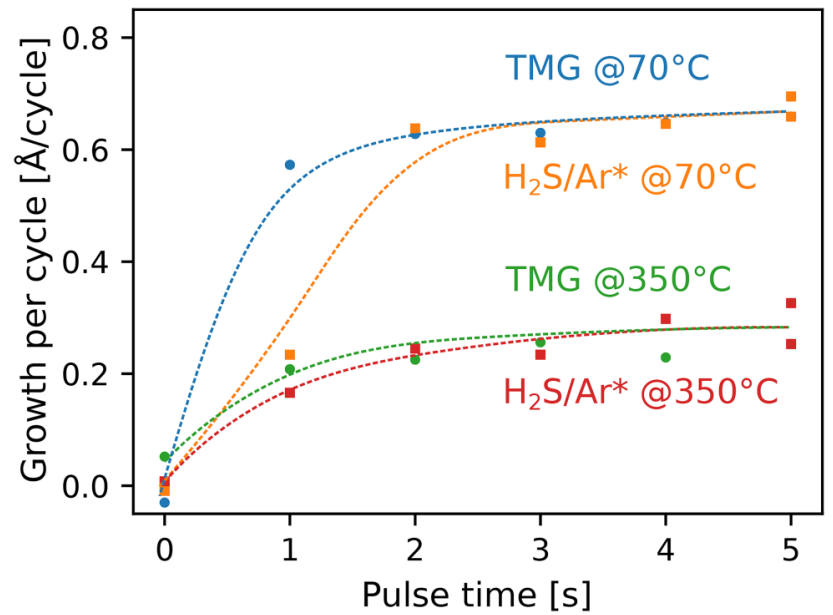

FIG. 3. Growth per cycle against the pulse time of TMG (circles) and $\mathrm{H}_{2} \mathrm{~S} / \mathrm{Ar}$ plasma (squares) for the PE-ALD $\mathrm{GaS}_{x}$ process deposited at 70 and $350{ }^{\circ} \mathrm{C}$. For both temperatures, the PE-ALD processes showed self-saturated behavior. Dashed lines are a guide to the eye.

spectrometry measurements were used to follow the evolution of specific mass-to-charge ratio $(\mathrm{m} / \mathrm{z})$ signals which correspond to potential precursor and reaction species: $\mathrm{H}_{2} \mathrm{~S}$ at $m / z=34$ [Fig. 4(b)], $\mathrm{CH}_{4}$ at $m / z=16$ [Fig. 4(c)], and $\mathrm{CS}_{2}$ at $m / z=76$ [Fig. 4(d)]. Different regions of interest were chosen and marked as $\mathbf{R}$ (references), $\mathbf{T}$ (thermal), and $\mathbf{P}$ (plasma) in Fig. 4. These three regions are discussed as follows:

References: Prior to the mass spectrometer measurements, the ALD chamber was primed by several $\mathrm{H}_{2} \mathrm{~S}$ plasma exposures. Then, $\mathrm{H}_{2} \mathrm{~S}$ plasma $\left(\mathbf{R}_{1}\right), \mathrm{H}_{2} \mathrm{~S}\left(\mathbf{R}_{2}\right)$, and TMG $\left(\mathbf{R}_{3}\right)$ were pulsed each three times as a reference measurement. During the $\mathrm{H}_{2} \mathrm{~S}$ plasma reference $\left(\mathbf{R}_{1}\right)$, there is an increase of the $\mathrm{m} / z=34$ and the $m / z=16$. The signal at $\mathrm{m} / z=16$ could originate from ionized sulfur coming from $\mathrm{H}_{2} \mathrm{~S}$.

During the $\mathrm{H}_{2} \mathrm{~S}$-pulses $\left(\mathbf{R}_{2}\right)$, there was an increase of the $m / z=34$ signal and the $m / z=16$ signal. An increase in the

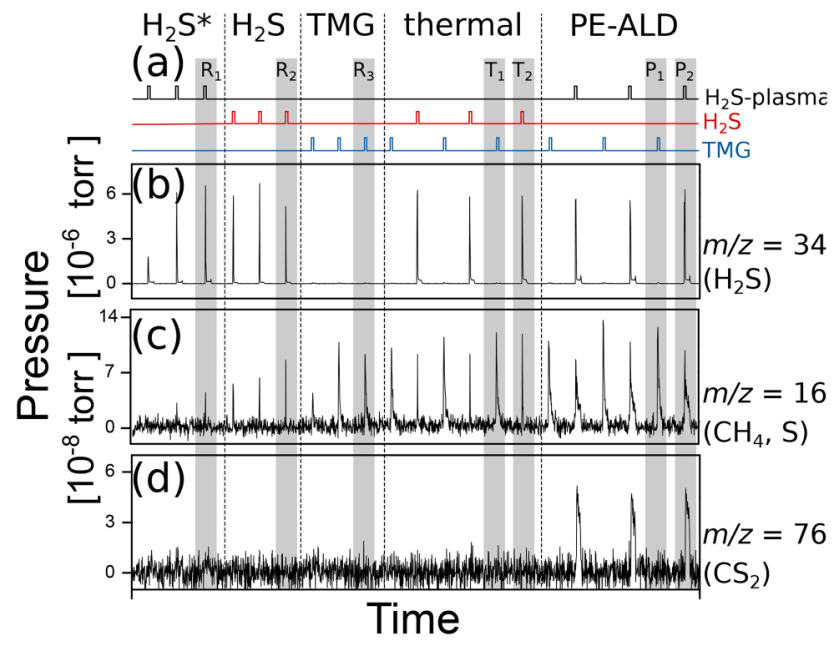

FIG. 4. (a) Schematic diagram of the process sequences used during mass spectrometry measurements. Partial pressure of (b) the $\mathrm{H}_{2} \mathrm{~S}$ signal at $m / z=34$, (c) the signal from methane at $m / z=16$, and (d) the $\mathrm{CS}_{2}$ signal at $m / z=76$ derived from multiple ion detection mass spectrometry measurements during a sequence of thermal and PE-ALD cycles. 
$m / z=16$ signal could originate from double ionized sulfur coming from $\mathrm{H}_{2} \mathrm{~S}$ which is broken down and ionized in the mass spectrometer. No signal at $m / z=76$ was registered.

During the TMG reference $\left(\mathbf{R}_{3}\right)$, there was only a signal for $m / z=16$ signal and no signal at $m / z=34$ and $m / z=76$ was detected. This was most likely caused by TMG which was broken down inside the mass spectrometer producing a methane signal.

Thermal ALD: During the thermal ALD process, first TMA $\left(\mathbf{T}_{1}\right)$ and then $\mathrm{H}_{2} \mathrm{~S}\left(\mathbf{T}_{2}\right)$ were pulsed. The obtained mass spectrometer signals during both half cycles were similar to the signals which were obtained during the reference measurements. Assuming a ligand exchange reaction between $\mathrm{H}_{2} \mathrm{~S}$ and TMG, methane is expected as a reaction product during both half reaction. However, as a mass spectrometer signal at $m / z=16$ was already visible during the reference pulses for $\mathrm{H}_{2} \mathrm{~S}\left(\mathbf{R}_{2}\right)$ and TMG $\left(\mathbf{R}_{3}\right)$, it is difficult to judge if there is an increase of this signal caused by additional methane.

PE-ALD: During the PE-ALD process, first TMA $\left(\mathbf{P}_{1}\right)$ and then $\mathrm{H}_{2} \mathrm{~S}$ plasma $\left(\mathbf{P}_{2}\right)$ were pulsed. The TMG half cycle $\left(\mathbf{P}_{1}\right)$ has a similar mass spectrometer signal as the TMG pulse during the thermal reaction $\left(\mathbf{T}_{1}\right)$. However, during the $\mathrm{H}_{2} \mathrm{~S}$ plasma half cycle $\left(\mathbf{P}_{2}\right)$, there was a mass spectrometer signal at $m / z=34$ and $m / z=76$. The signal at $m / z=76$ was most likely caused by $\mathrm{CS}_{2}$ which is a reaction product of a combustion reaction. Another typical reaction product of a combustion reaction is $\mathrm{CS}$ which was however not detected. The presence of $\mathrm{CS}_{2}$ during the $\mathrm{H}_{2} \mathrm{~S}$ plasma is a strong indication that a combustion reaction is taking place.

Figure 5 shows a schematic display of a possible reaction pathway during the thermal TMG $+\mathrm{H}_{2} \mathrm{~S}$ ALD process and the $\mathrm{TMG}+\mathrm{H}_{2} \mathrm{~S} / \mathrm{Ar}$ plasma PE-ALD process. During the thermal reaction, TMG reacts with free SH surface groups in order to form $\mathrm{GaCH}_{3}$ surface groups and $\mathrm{CH}_{4}$ which is released as a byproduct. In the following half reaction, $\mathrm{H}_{2} \mathrm{~S}$

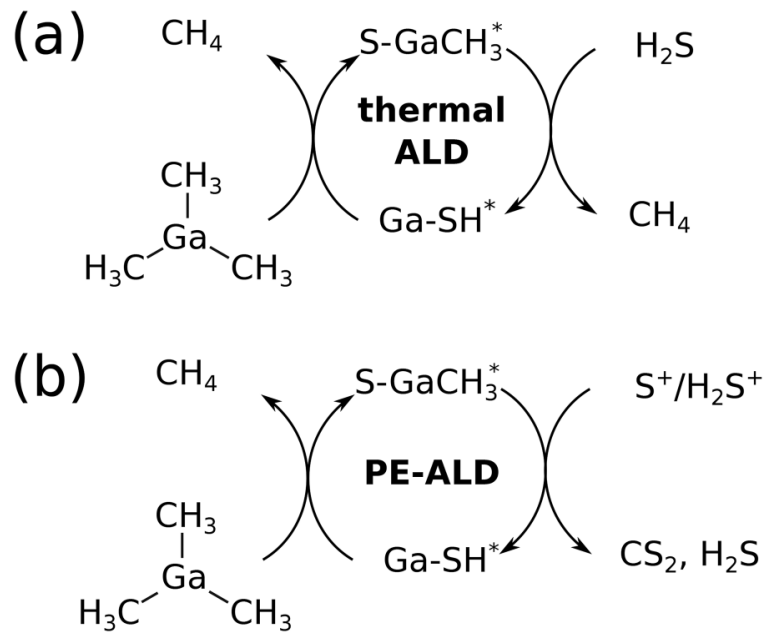

FIG. 5. Schematic reaction pathway of (a) the thermal $\mathrm{TMG}+\mathrm{H}_{2} \mathrm{~S}$ reaction and (b) the plasma enhanced TMG $+\mathrm{H}_{2} \mathrm{~S}$ plasma reaction. Surface groups are marked by *. During the first half reaction in the thermal process and the plasma enhanced process, TMG reacts with $\mathrm{SH}$ surface sites and forms $\mathrm{CH}_{4}$ and $-\mathrm{GaCH}_{3}^{*}$. In the second half reaction of the thermal process (a), $\mathrm{H}_{2} \mathrm{~S}$ reacts with $-\mathrm{GaCH}_{3}^{*}$ and forms $\mathrm{CH}_{4}$ and $\mathrm{SH}^{*}$. In the plasma enhanced process (b), $\mathrm{SH}_{x}$ ions/radicals react with $-\mathrm{GaCH}_{3}^{*}$ and form $\mathrm{SH}^{*}, \mathrm{H}_{2} \mathrm{~S}$, and $\mathrm{CS}_{2}$. reacts with $\mathrm{GaCH}_{3}$ surface groups in order to form again $\mathrm{SH}$ surface groups and $\mathrm{CH}_{4}$ as a reaction product. Unfortunately, growth for the thermal process stopped. A similar behavior was observed for the TMG $+\mathrm{H}_{2} \mathrm{O}$ ALD process where also no growth was observed for the thermal process. ${ }^{29}$ This could be due to surface poisoning with methylgroups which are not sufficiently reactive and only partially removed, and potentially even cross-linked in the presence of $\mathrm{H}_{2} \mathrm{~S}$. Fourier transformed infrared measurements (FTIR) could give more insight about the deposition mechanism and reveal why no growth was observed for the thermal process. Unfortunately, FTIR measurements were not possible on the used ALD reactor.

In analogy to the reaction mechanism of the thermal TMA $+\mathrm{H}_{2} \mathrm{O}$ and plasma enhanced TMA $+\mathrm{O}_{2}$ plasma processes or the PE-ALD of $\mathrm{Al}_{2} \mathrm{~S}_{3}$, a second reaction mechanism using $\mathrm{H}_{2} \mathrm{~S}$ plasma can be proposed. ${ }^{32-34,26}$ In this PE-ALD reaction [Fig. 5(b)], the first half cycle is similar to the thermal ALD reaction: TMG reacts with free $\mathrm{SH}$ surface groups in order to form $\mathrm{GaCH}_{3}$ surface groups and $\mathrm{CH}_{4}$. During the $\mathrm{H}_{2} \mathrm{~S}$ plasma exposure, $\mathrm{SH}_{x}$ ions and radicals are formed. These can react with $\mathrm{GaCH}_{3}$ surface groups to form $\mathrm{SH}^{*}$ groups and $\mathrm{H}_{2} \mathrm{~S}$, $\mathrm{CS}_{2}$, and CS as byproducts. This is in analogy to the combustion reaction between TMA $+\mathrm{O}_{2}$ plasma where $\mathrm{CO}_{2}, \mathrm{CO}$, and $\mathrm{H}_{2} \mathrm{O}$ are formed as reaction products.

In previous studies, we investigated the optical emission spectrum of $\mathrm{H}_{2} \mathrm{~S}$ plasma. ${ }^{25,26}$ These studies revealed the presence of $\mathrm{H}^{+}$and $\mathrm{S}^{+}$ions. Furthermore, $\mathrm{H}_{2} \mathrm{~S}^{+}$radicals were detected while no optical emission from the metals involved in the ALD process was found.

\section{Material properties}

XRD measurements were performed in order to investigate the crystallinity of $\mathrm{GaS}_{x}$ thin films deposited by PE-ALD. All $\mathrm{GaS}_{x}$ thin films deposited at 70,150 , and $300^{\circ} \mathrm{C}$ were amorphous and even annealing to $700{ }^{\circ} \mathrm{C}$ did not result in any detectable crystallinity.

The composition of $\mathrm{GaS}_{x}$ thin films was checked with XPS measurements. Figure 6 shows the survey spectrum of $\mathrm{GaS}_{x}$ deposited by PE-ALD at $150^{\circ} \mathrm{C}$. The surface was

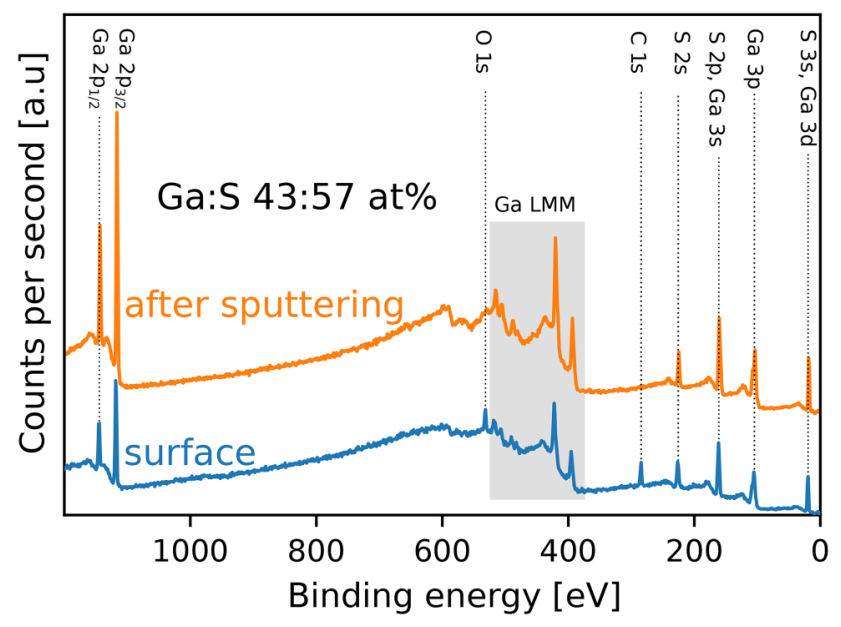

FIG. 6. XPS survey spectrum of $\mathrm{GaS}_{x}$ deposited by PE-ALD at $150^{\circ} \mathrm{C}$ before and after sputter cleaning of the surface. 


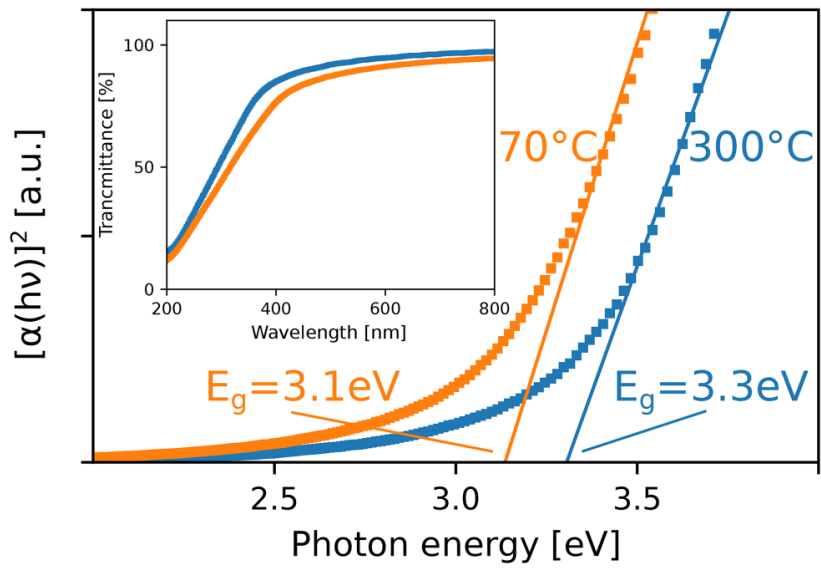

Fig. 7. Tauc-plot for a 15 and $17 \mathrm{~nm}$ thick $\mathrm{GaS}_{x}$ thin film deposited with PE-ALD on quartz substrates at 70 and $300{ }^{\circ} \mathrm{C}$, respectively. The band gap energy is determined from the linear fit to the absorption edge and by interpolation to zero as indicated. The inset shows the transmittance spectrum of the same films corrected for the transmittance of the bare quartz substrate.

oxidized and contaminated with carbon. After slight sputter etching, the oxygen and carbon content was below the detection limit of approximately $1 \%$, indicating that the bulk of $\mathrm{GaS}_{x}$ does not contain major contaminants. The atomic composition of the $\mathrm{GaS}_{x}$ thin film was estimated by fitting and quantifying the $S 2 s$ and $G a 2 p$ peaks. The $S 2 p$ peak was not used as it overlaps with the Ga $3 \mathrm{~s}$ peak. ${ }^{35}$ The ratio between $\mathrm{Ga}$ and $\mathrm{S}$ was found to be 43:57. No significant change in the Ga:S ratio was found between deposition at different temperatures.

Optical transmittance measurements were used to determine the optical properties of the as-deposited $\mathrm{GaS}_{x}$ films. For this, $\mathrm{GaS}_{x}$ thin films were deposited at different temperatures on quartz substrates. The transmittance of these films is shown in the inset of Fig. 7. The layers had a transmission of nearly $100 \%$ in the visible region. This is an important property for many optical applications of $\mathrm{GaS}_{x}$. To determine the energy band gap $\left(E_{g}\right)$ of the material, a Tauc-plot ${ }^{36,37}$ was used. The absorption coefficient $\alpha$ was calculated from the transmittance $T$ and the film thickness $d$, as $\alpha=\ln (T) / d$.

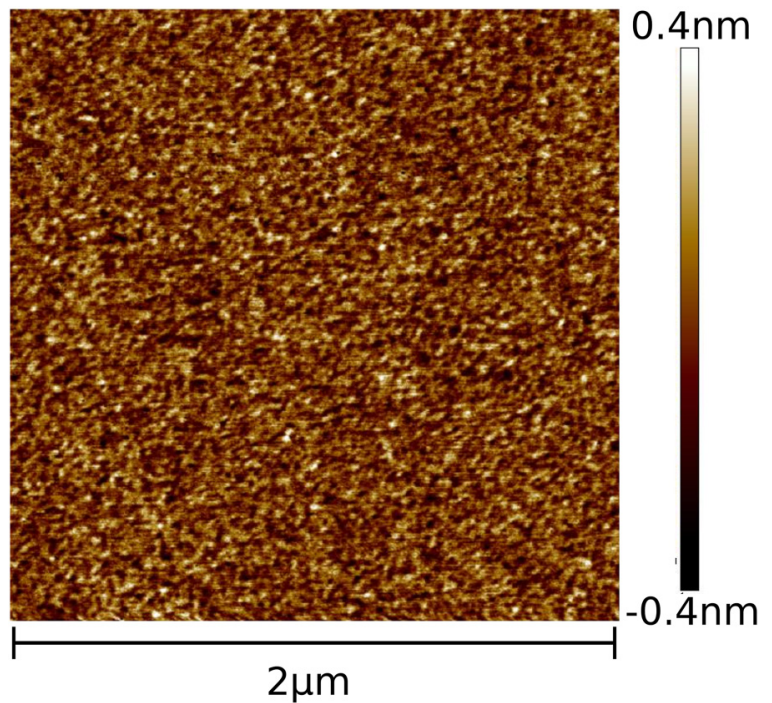

Fig. 8. AFM scan of $20 \mathrm{~nm}$ PE-ALD GaS $x$ deposited at $70{ }^{\circ} \mathrm{C}$ on Si covered with native $\mathrm{SiO}_{2}$. The RMS roughness was estimated to be $0.1 \mathrm{~nm}$.

Since $\mathrm{GaS}_{x}$ has a direct band gap, ${ }^{38}$ it can be determined from the Tauc-plot by interpolating the fit of the linear part of the absorption edge to zero. For the PE-ALD process deposited at 70 and $300{ }^{\circ} \mathrm{C}$, a band gap of 3.13 and $3.30 \mathrm{eV}$, respectively, was found. These values are close to values reported in literature for $\mathrm{GaS}(3.05 \mathrm{eV}) .^{38}$

Figure 8 shows the AFM scan of a $20 \mathrm{~nm}$ PE-ALD GaS $x$ deposited at $70{ }^{\circ} \mathrm{C}$ on $\mathrm{Si}$ covered with native $\mathrm{SiO}_{2}$. The AFM scan revealed a smooth surface. The RMS roughness was calculated on an area of $2 \mu \mathrm{m} \times 2 \mu \mathrm{m}$ and it was estimated to be $0.1 \mathrm{~nm}$. SEM images revealed continuous and smooth layers.

For plasma enhanced ALD of oxides, it is well-known that achieving conformality can be challenging because of recombination of the radicals that are required to reach the growth. ${ }^{39,40}$ Therefore, the conformality of the $\mathrm{GaS}_{x}$ PE-ALD process on nonplanar substrates was studied by coating Si micropillars with $\mathrm{GaS}_{x}$ thin films. ${ }^{41}$ These $\mathrm{Si}$ micropillars had a width of $2 \mu \mathrm{m}$, height of $50 \mu \mathrm{m}$, and a
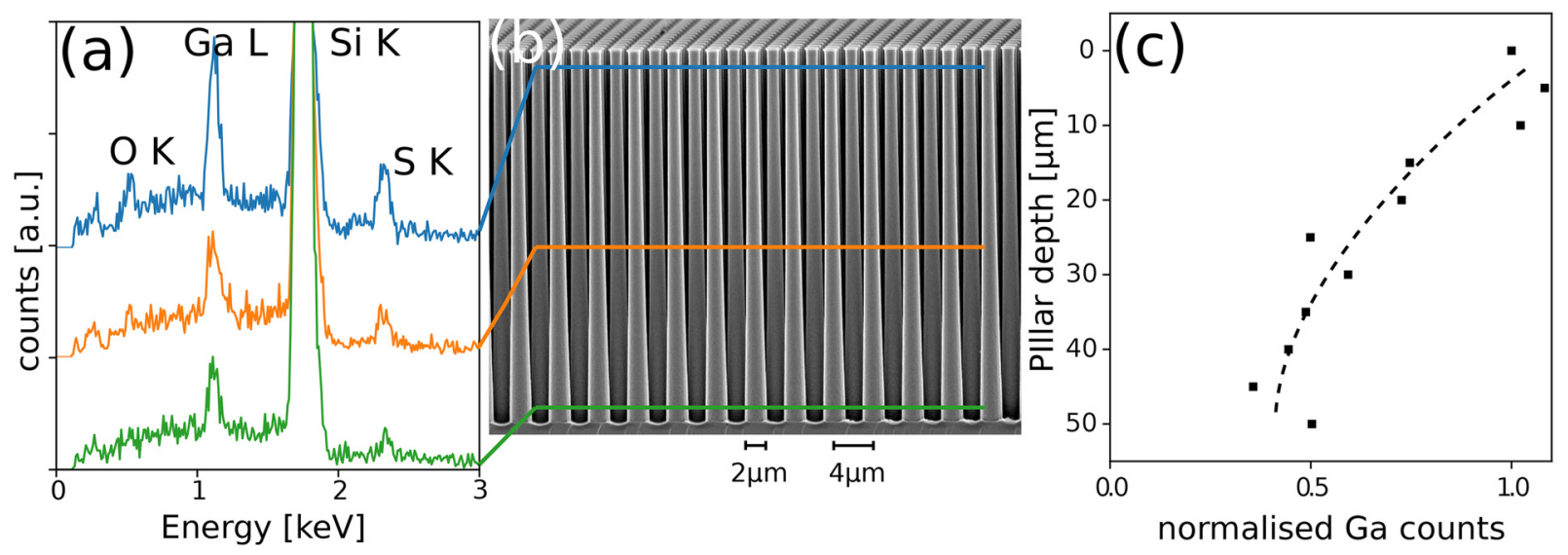

FIG. 9. (a) EDX spectra obtained from line scans at different positions along Si micropillars. (b) SEM cross section of Si micropillars coated with 230 cycles of

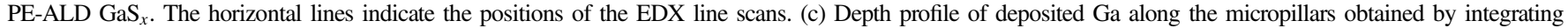
over the Ga L peaks from the EDX spectra. The Ga counts are normalized to the Ga counts found on the top of the micropillars. Dashed lines are a guide to the eye. 
center-to-center spacing of $4 \mu \mathrm{m}$. Since the TMG was pumped very efficiently out of the ALD chamber, static TMG pulses were used. For the static pulse, the plate valve connecting the chamber to the turbo pump was closed and the chamber was filled with TMG until a pressure of $5^{\cdot} 10^{-3}$ mbar was reached. After $10 \mathrm{~s}$, the chamber was pumped again until the base pressure was reached. The deposition parameters of the $\mathrm{H}_{2} \mathrm{~S} / \mathrm{Ar}$ plasma cycle were not optimized. A deposition temperature of $70^{\circ} \mathrm{C}$ was used. After the deposition, cross sections of these samples were investigated by SEM. Figure 9(b) shows the SEM cross section of the micropillars coated with 230 cycles of PE-ALD $\mathrm{GaS}_{x}$. Since no contrast between the $\mathrm{Si}$ micropillars and $\mathrm{GaS}_{x}$ coating was visible in the SEM image, the sample was investigated by energy-dispersive $\mathrm{x}$-ray spectroscopy. EDX line scans were performed at 11 different positions along the micropillars. Three of them are indicated by the vertical lines in Fig. 9(b). Figure 9(a) shows the EDX spectra of these different line scans. The oxygen peak near the top can be related to a layer of $\mathrm{SiO}_{2}$ on top of the micropillars. $\mathrm{Ga}$ and $\mathrm{S}$ can be detected even near the bottom of the pillars. However, there is a clear difference between the Ga signal from the top and the signal from the bottom of the micropillars. The total amount of deposited $\mathrm{GaS}_{x}$ was estimated from the EDX scans by integrating over the Ga L peak. Figure 9(c) shows the amount of $\mathrm{Ga}$ as derived from the integration at different depths along the pillars. With increasing depth along the pillars, the amount of detected Ga decreased. At the bottom of the micropillars, there was approximately 50\% of the amount of $\mathrm{Ga}$ in comparison to the top of the pillars.

\section{CONCLUSIONS}

A new plasma enhanced ALD process was developed for $\mathrm{GaS}_{x}$ using TMG and $\mathrm{H}_{2} \mathrm{~S} / \mathrm{Ar}$ plasma. The growth of the thermal TMG $+\mathrm{H}_{2} \mathrm{~S}$ process stopped after two cycles. We showed that a combustion-type reaction during the plasma step is crucial in order to realize the ALD growth of $\mathrm{GaS}_{x}$. In situ spectroscopic ellipsometry and ex situ x-ray reflectometry were used to study the growth characteristics of PE-ALD GaS $x$. We found that the PE-ALD GaS $x$ process grows linearly without any nucleation delay. The PE-ALD process is self-saturating in the range from 70 to $350^{\circ} \mathrm{C}$. The GPC is constant from 70 to $250^{\circ} \mathrm{C}$ with approximately $0.65 \AA /$ cycle and drops at high temperature down to $0.3 \AA /$ cycle. The properties of the deposited films were investigated ex situ using x-ray photoelectron spectroscopy, x-ray diffraction, and SEM/EDX measurements. $\mathrm{GaS}_{x}$ thin films were amorphous as deposited, and the films were continuous without any pinholes. The $\mathrm{GaS}_{x}$ thin films were free from oxygen and carbon. Finally, optical transmittance measurements showed that the $\mathrm{GaS}_{x}$ thin films had a transmittance of $>90 \%$ and a band gap of $3.1-3.3 \mathrm{eV}$.

\section{ACKNOWLEDGMENTS}

J.K. acknowledges the Agency for Innovation by Science and Technology (IWT) for a Ph.D. scholarship. The authors acknowledge the financial support from the UGENT-
GOA-01G01513 and Hercules AUGE/09/014 projects. The authors thank P. Vereecken for providing the silicon micropillar structures. Finally, they thank Karl Opsomer and Matthias Minjauw for XPS measurements, Olivier Janssens for SEM/EDX work, and Jo Sys for technical support and assistance in maintaining the ALD reactor.

${ }^{1}$ R. M. A. Leith, H. J. M. Heijligers, and C. W. M. v. d. Heijden, J. Electrochem. Soc. 113, 798 (1966).

${ }^{2}$ C. Sanz, C. Guillén, and M. T. Gutiérrez, J. Phys. D Appl. Phys. 42, 085108 (2009).

${ }^{3}$ P. N. Kumta and S. H. Risbud, J. Mater. Sci. 29, 1135 (1994).

${ }^{4}$ C. Y. Huang, W. C. Lee, and A. Lin, J. Appl. Phys. 120, 094502 (2016).

${ }^{5}$ G. Micocci, R. Rella, and A. Tepore, Thin Solid Films 172, 179 (1989).

${ }^{6}$ K. Morii, H. Ikeda, and Y. Nakayama, Mater. Lett. 17, 274 (1993).

${ }^{7}$ X. Y. Chen, X. Y. Hou, X. A. Cao, X. M. Ding, L. Y. Chen, G. Q. Zhao, and X. Wang, J. Cryst. Growth 173, 51 (1997).

${ }^{8}$ N. Okamoto and H. Tanaka, Mater. Sci. Semicond. Process. 2, 13 (1999).

${ }^{9}$ J. S. Herman and F. L. Terry, Jr., Appl. Phys. Lett. 60, 716 (1992).

${ }^{10}$ I. S. R. Sastry, C. F. Bacalski, and J. McKittrick, J. Electrochem. Soc. 146, 4316 (1999).

${ }^{11}$ S. Okamoto, K. Tanaka, and Y. Inoue, Appl. Phys. Lett. 76, 946 (2000).

${ }^{12} \mathrm{X}$. Meng et al., Adv. Funct. Mater. 24, 5435 (2014).

${ }^{13}$ M. Ohyama, H. Ito, and M. Takeuchi, Jpn. J. Appl. Phys. 44, 4780 (2005).

${ }^{14}$ A. N. MacInnes, M. B. Power, and A. R. Barron, Chem. Mater. 4, 11 (1992).

${ }^{15}$ A. N. MacInnes, M. B. Power, and A. R. Barron, Chem. Mater. 5, 1344 (1993).

${ }^{16}$ A. R. Barron, Adv. Mater. Opt. Electron. 5, 245 (1995).

${ }^{17}$ S. Suh and D. M. Hoffman, Chem. Mater. 12, 2794 (2000).

${ }^{18}$ R. L. Puurunen, J. Appl. Phys. 97, 121301 (2005).

${ }^{19}$ S. M. George, Chem. Rev. 110, 111 (2010).

${ }^{20}$ V. Miikkulainen, M. Leskelä, M. Ritala, and R. L. Puurunen, J. Appl. Phys. 113, 021301 (2013).

${ }^{21}$ X. Meng, J. A. Libera, T. T. Fister, H. Zhou, J. K. Hedlund, P. Fenter, and J. W. Elam, Chem. Mater. 26, 1029 (2014).

${ }^{22}$ N. Schneider, M. Frégnaux, M. Bouttemy, F. Donsanti, A. Etcheberry, and D. Lincot, Mater. Today Chem. 10, 142 (2018).

${ }^{23}$ C. Goehry and N. Schneider, J. Phys. Chem. C 121, 5871 (2017).

${ }^{24}$ Y. Jang, S. Yeo, H.-B.-R. Lee, H. Kim, and S.-H. Kim, Appl. Surf. Sci. 365, 160 (2016).

${ }^{25}$ J. Kuhs, T. Dobbelaere, Z. Hens, and C. Detavernier, J. Vac. Sci. Technol. A 35, $01 \mathrm{~B} 111$ (2017).

${ }^{26}$ J. Kuhs, Z. Hens, and C. Detavernier, J. Vac. Sci. Technol. A 36, 01 A113 (2018).

${ }^{27}$ N. P. Dasgupta, J. F. Mack, M. C. Langston, A. Bousetta, and F. B. Prinz, Rev. Sci. Instrum. 81, 044102 (2010).

${ }^{28}$ C. D. Wagner, W. M. Riggs, L. E. Davis, and J. F. Moulder, Handbook of X-ray Photoelectron Spectroscopy (Perkin-Elmer Corporation, Eden Prairie, MN, 1979).

${ }^{29}$ D. J. Comstock and J. W. Elam, Chem. Mater. 24, 4011 (2012).

${ }^{30}$ H. B. Profijt, S. E. Potts, M. C. M. van de Sanden, and W. M. M. Kessels, J. Vac. Sci. Technol. A 29, 050801 (2011).

${ }^{31}$ R. W. Johnson, A. Hultqvist, and S. F. Bent, Mater. Today 17, 236 (2014).

${ }^{32}$ S. B. S. Heil, P. Kudlacek, E. Langereis, R. Engeln, M. C. M. van de Sanden, and W. M. M. Kessels, Appl. Phys. Lett. 89, 131505 (2006).

${ }^{33}$ S. B. S. Heil, J. L. van Hemmen, M. C. M. van de Sanden, and W. M. M. Kessels, J. Appl. Phys. 103, 103302 (2008).

${ }^{34}$ E. Langereis, J. Keijmel, W. M. M. Kessels, M. C. M. van de Sanden, and W. M. M. Kessels, Appl. Phys. Lett. 92, 231904 (2008).

${ }^{35}$ A. Harvey et al., Chem. Mater. 27, 3483 (2015).

${ }^{36}$ J. Tauc, R. Grigorovici, and A. Vancu, Phys. Status Solidi 15, 627 (1966).

${ }^{37}$ J. Tauc, A. Menth, and D. L. Wood, Phys. Rev. Lett. 25, 749 (1970).

${ }^{38}$ M. Lazell, P. O'Brien, D. J. Otway, and J. H. Park, J. Chem. Soc. Dalton Trans. 24, 4479 (2000).

${ }^{39}$ J. Dendooven, D. Deduytsche, J. Musschoot, R. L. Vanmeirhaeghe, and C. Detavernier, J. Electrochem. Soc. 156, P63 (2009).

${ }^{40}$ J. Dendooven, D. Deduytsche, J. Musschoot, R. L. Vanmeirhaeghe, and C. Detavernier, J. Electrochem. Soc. 157, G111 (2010).

${ }^{41}$ V. Cremers, F. Geenen, C. Detavernier, and J. Dendooven, J. Vac. Sci. Technol. A 35, 01B115 (2017). 